\title{
ASSESSMENT OF RAILWAY STATION MODERNISATION COMBINING RISK ANALYSIS WITH MULTI-CRITERIA ANALYSIS
}

\footnotetext{
When modernising train stations, several options are usually available for the layout of the tracks and its parameters. The best option is chosen by assessing different criteria; it is not an exact procedure, but a compromise between often different perspectives. Many methods are available to aid the decision-making process in these situations; the authors of this article apply mutually combined multi-criteria and qualitative risk analysis to assess two self-proposed options for the modernisation of the Bakov nad Jizerou station (situated in Central Bohemia in the Czech Republic).

Keywords: Railway station, railway modernisation, risk analysis, multi-criteria analysis.
}

\section{Introduction}

When modernising not only traffic infrastructure, an investor usually selects the project to be undertaken out of several options. It is not an easy task to compare particular options in order to reach the modernisation objectives; firstly it is problematic to define the comparison criteria, secondly it is also problematic to establish the methodology of assessing the qualitative criteria, and finally different stakeholders and experts tend to attribute different significance to particular criteria.

Regarding the example of the modernisation of the Bakov nad Jizerou junction station, situated in Central Bohemia, Czech Republic, the authors of this article introduce two self-proposed station modernisation options which currently represent the most common approaches to the modernisation of stations in the Czech Republic, aside from the Trans-European Rail network. Consequently, the proposed project options are assessed through the mutual combination of multi-criteria and qualitative risk analysis.

\section{Modernisation of the Bakov nad Jizerou station}

The Bakov nad Jizerou train station is a junction station for two single-track lines (Prague - Turnov and Bakov nad Jizerou Ceska Lipa - Jedlova). The importance of this station is mainly as a passenger transport to transit between connecting trains. Fast trains on both lines oriented in the same direction meet here with a two-hour frequency, interwoven with local passenger trains with the same time interval. The importance for the town resident traffic is minimal, given the location of the station. Regarding freight transport, the station mainly serves as a crossing for through freight trains, to assemble pick up goods trains and to stable train sets.

\subsection{Current state}

In the Bakov nad Jizerou station, the branching of the lines into two main tracks is carried out at a level in the southern station head by connecting the two main station tracks with a scissors crossover in the northern station head. The station tracks consist of nine running tracks and seven loading tracks out of which six are dead-end tracks. In the tracks in front of the station building there are five single level platforms with concrete slabs that are accessible from the station building by a wide foot level crossing and sloping ramps. Although the platforms are wheelchair accessible from the covered porch of the station building, they are not so directly from the station building or the station forecourt.

A disadvantage of the current station layout from the point of view of passenger transport is the separate level platforms that due to their width and height do not provide sufficient comfort and safety to passengers. The disposition layout of the tracks may be considered adequate under the given circumstances, therefore the proposed options of modernisation deal particularly with the

\footnotetext{
* Tomas Javorik, Lukas Tyfa

Czech Technical University Prague, Faculty of Transportation Sciences, Czech Republic

E-mail: tyfa@fd.cvut.cz
} 
layout of platforms: their increase in height to $550 \mathrm{~mm}$ above the rail top, safe and wheelchair accessible platforms, and a solid surface over the whole width of the platform. Both proposals result from a stabilised extension and organisation of traffic at the station [1].

\subsection{Modernisation proposals}

Under option 1 of the modernisation proposal, a "semi-island platform" (Fig. 1) with two edges is laid in the space of the abolished track no. 5. Similarly, a single-island platform (platform edge by track no. 1) is laid in the space of the directional track no. 2. Both platforms are accessible from their heads by sloping ramps and a central foot level crossing. The utilisation of platform edges is envisaged in a way that the trains will not have to run over the crossing before stopping (nor when meeting and passing each other). By adapting the position of track no. 4 and its deadend termination, a space by the station building is created for the placement of another two-sided semi-island platform at which local trains would stop in particular.
Under option 2, an "island platform" (Fig. 2) is laid in the space of the truncated track no. 3. It is a two-sided island platform with a related section - a bay platform (intended for local trains). Furthermore, an outside platform is established in front of the station building. Access to the island platform is provided using the area of the outside platform in front of the station building via an underpass with staircases and elevators.

\subsection{Establishing the modernisation options' parameters for further analysis}

In order to assess the options using multi-criteria analysis, the transition times and provisional budget for the modernisation investment costs were calculated for each option.

The calculation of transition times results from a methodology developed within the [2] and [3] that establishes the speed of transition by passengers given the characteristics of the access path used (horizontal walking in general, walking on stairs, walking at a foot level crossing etc.) and that results from a range of calculated values. The times for all transition options in the station (i.e. between trains standing at all platform edges) were

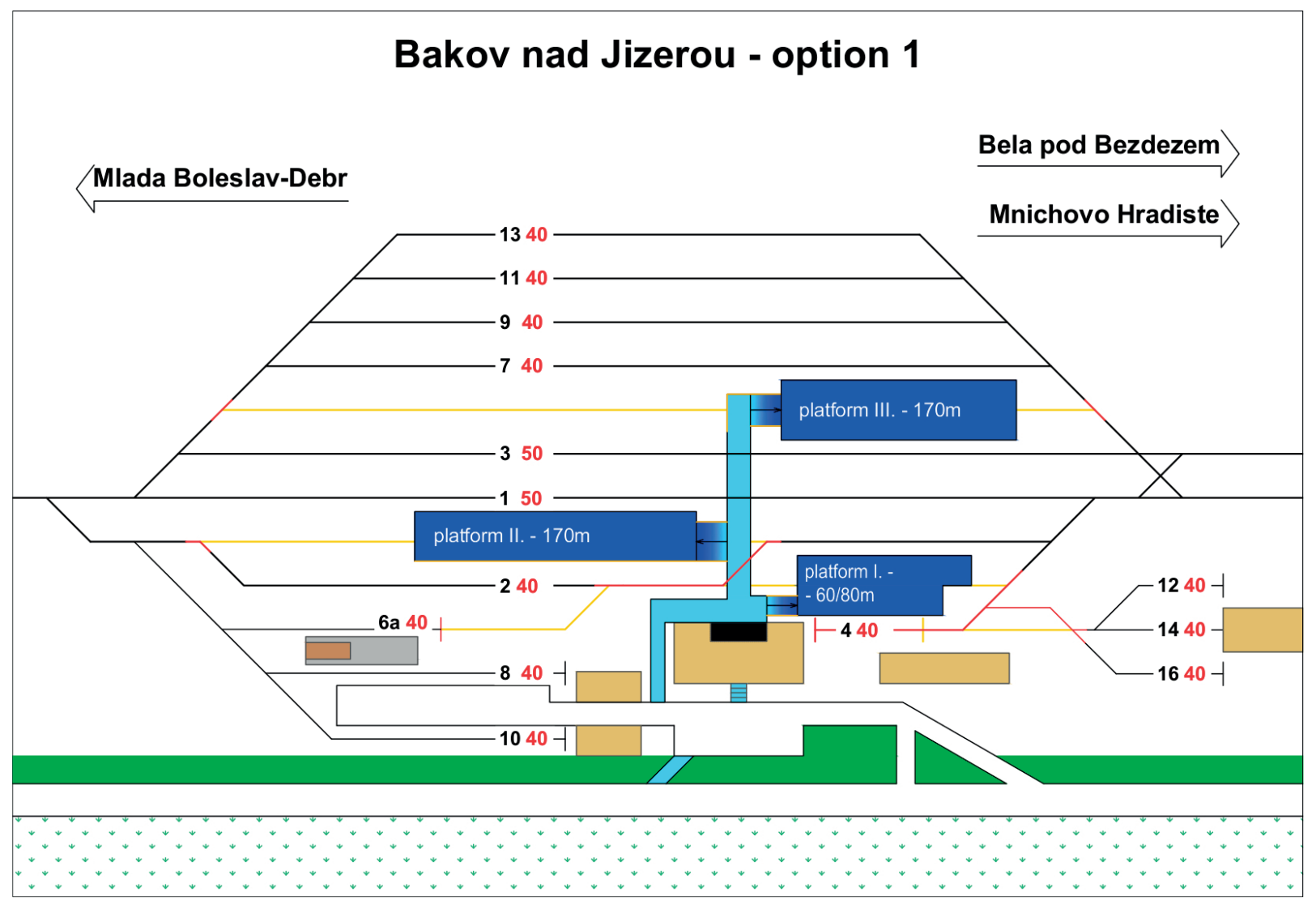

Fig. 1 Option 1 of the station modernisation 


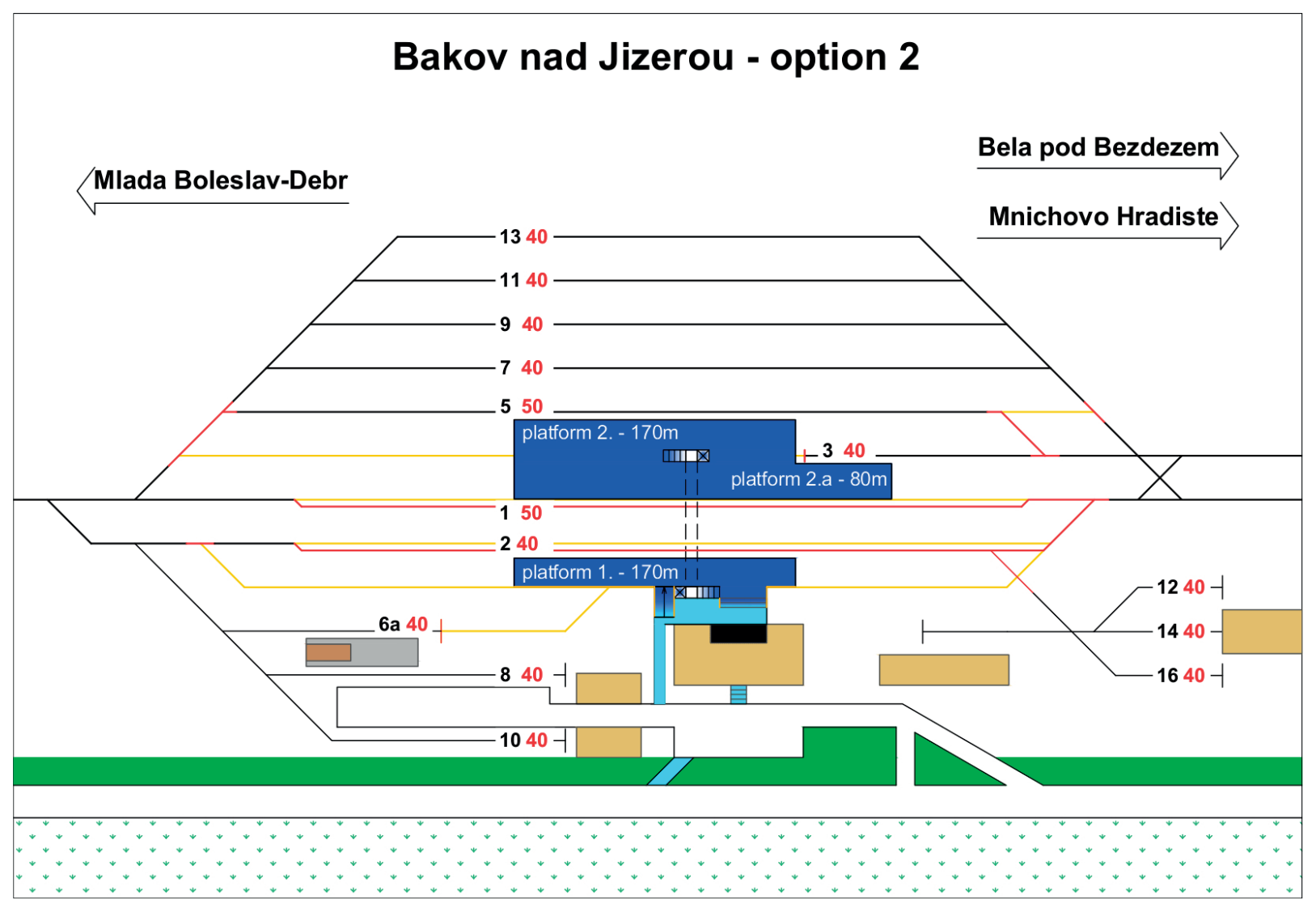

Fig. 2 Option 2 of the station modernisation

calculated, both the maximum (i.e. exiting from the furthermost doors of a train formation to the underpass staircase, and from the ramp to the central crossing and boarding back again at the furthermost doors of a train formation) and the mean. Quite surprisingly transition times under option 2 were significantly shorter, even though the passengers must use a seemingly more time-consuming access route to the platform via the underpass.

For calculating a provisional budget, a simplified station site plan was made for both options. The calculation itself comprises the complete station reconstruction implementation process, from the design works to the complete construction and all construction structures and operation sets (incl. safety systems). Unit prices are based on 2011 price levels. Because an underpass needs to be built, the investment costs are slightly higher under option 2 which is therefore construction and organisation-wise more exacting.

\section{Comparison between the station modernisation options}

\subsection{Risk analysis}

Risks, as an eventuality (probability) of an undesirable event, may be assessed by the methods of qualitative and quantitative risk analysis in any system. In the quantitative methods, the probability that an event shall occur and its consequences may be determined in measurable units. By contrast, qualitative methods describe risks, fault modes and scenarios of the possible consequences of undesirable states based on the opinions of experts, whereas the outputs in these cases are presented on a relative scale. In order to assess risks from a railway construction, given the (fortunately) small scale of real extraordinary events, it is convenient to employ qualitative methods. The group of experts used for the risk assessment must be sufficiently numerous and heterogeneous in order to eliminate the subjective views of any individual assessor. To assess the train station modernisation options, the FMEA (Failure Mode and Effect Analysis) analytic method was chosen to be the most suitable, i.e. its modification SAFMEA (Statistically Adjusted Failure Mode and Effect Analysis) [4]. 
When applying the SAFMEA method it is advanced in several phases. In the first (preparatory) phase, the aspects to be dealt with in the risk analysis are chosen. In the case described, not only the station situation layout, but also the operational perspective is concerned. At the same time, the expert group is established and in this case was composed of twenty experts with an extensive expertise in the field of rail transport. In the second phase, the main project segments and single risk factors (RF) within them are defined. The project team established 21 risk factors in the 7 project segments (A to $G$ ) - see Table 1. Furthermore, the scales with explanations of the RF consequences severity assessment and the RF subjective occurrence probability were created. In the described application, the same four-point scale 1-4 was chosen for both values. Following instructions and becoming acquainted with the assessed options, the experts fill the prepared form with the event severity value for each of the RF and with the event

\begin{tabular}{|c|c|}
\hline $\mathrm{A} 1$ & rail traffic flow disturbance during the station modernisation construction works \\
\hline A2 & rail traffic safety disturbance during the station modernisation construction works \\
\hline A3 & permanent outflow of passengers due to the station modernisation construction works \\
\hline A4 & $\begin{array}{l}\text { definite termination of embarking and disembarking at the station due to the station modernisation construction works (transport ontractors } \\
\text { will find another alternative and will not return to the station) }\end{array}$ \\
\hline B1 & inability to acquire (get allocated) investment financial resources for the station modernisation \\
\hline B2 & $\begin{array}{l}\text { inability to acquire (get allocated) financial means for the operation and maintenance of equipment and passenger transport after the station } \\
\text { modernisation (platforms, underpass/central crossing) }\end{array}$ \\
\hline B3 & $\begin{array}{l}\text { low efficiency of the financial means spent on the implementation of the assessed modernisation option given a minor improvement of the } \\
\text { current state }\end{array}$ \\
\hline $\mathrm{C} 1$ & damaging the passenger transport equipment after the station modernisation due to vandalism \\
\hline $\mathrm{C} 2$ & $\begin{array}{l}\text { outflow of passengers due to criminal activity (mugging, robbery, thievery, harassment...) committed in the passenger transport facilities } \\
\text { after the station modernisation (platforms, underpass/central crossing) or the subjective feeling of being threatened by crime }\end{array}$ \\
\hline D1 & railway carriage hitting a person on the tracks (track) \\
\hline D2 & collision between railway carriages \\
\hline D3 & outflow of passengers due to their subjective feeling of being endangered by railway traffic \\
\hline E1 & outflow of passengers due to their subjective feeling of poor comfort \\
\hline F1 & $\begin{array}{l}\text { negative influence on designing the train service planning given a long stay of trains at the station due to long transition time between } \\
\text { connecting trains }\end{array}$ \\
\hline F2 & $\begin{array}{l}\text { negative influence on drawing the train service planning given the service technology at the station (train routes crossings, influencing the } \\
\text { train shunting and travel...) }\end{array}$ \\
\hline F3 & negative influence on drawing the train service planning due to exhaustion of capacity of the running tracks at the station \\
\hline F4 & negative influence on drawing the train service planning due to exhaustion of capacity of the platform edges at the station \\
\hline G1 & emergence of operational irregularities due to long transition times between connecting trains at the station \\
\hline G2 & $\begin{array}{l}\text { emergence of operational irregularities given the service technology at the station (train routes crossings, influencing the train shunting and } \\
\text { travel...) }\end{array}$ \\
\hline G3 & emergence of operational irregularities due to exhaustion of capacity of the running tracks at the station \\
\hline G4 & emergence of operational irregularities due to exhaustion of capacity of the platform edges at the station \\
\hline
\end{tabular}




\begin{tabular}{|c|c|c|c|c|c|}
\hline & & \multicolumn{4}{|c|}{ Event probability $(p)$} \\
\hline \multicolumn{2}{|c|}{ Event severity (m) } & 1 & 2 & 3 & 4 \\
\hline$m$ & $2^{m}$ & \multicolumn{4}{|c|}{ Risk assessment (r) and its severity status } \\
\hline 1 & 2 & 2 & 4 & 6 & 8 \\
\hline 2 & 4 & 4 & 8 & 12 & 16 \\
\hline 3 & 8 & 8 & 16 & 24 & 32 \\
\hline 4 & 16 & 16 & 32 & 48 & 64 \\
\hline $2-12$ & $2-14$ & \multicolumn{4}{|c|}{ acceptable risk } \\
\hline $16-24$ & $14-28$ & \multicolumn{4}{|c|}{ conditionally acceptable risk } \\
\hline $32-64$ & $28-64$ & \multicolumn{4}{|c|}{ unacceptable risk } \\
\hline
\end{tabular}

probability characterised by the given RF for each option. Single RFs are assessed by the so-called risk assessment ${ }^{1}$ - see (1).

$r_{i}=2^{m i} \cdot p_{i}$

where:

$r_{i}$ - risk assessment of the risk factor $i[-]$

$m_{i}$ - event severity $i[-]$

$p_{i}$ - event probability $i[-]$

The filled forms are consequently evaluated by descriptive statistics. Each RF under each option is assigned a severity status, i.e. according to the $20 \%$ trimmed average of the risk assessment (see Figs. 3 and 4) the given RF under the given option is classified as an acceptable, conditionally acceptable or unacceptable risk - see Table 2.

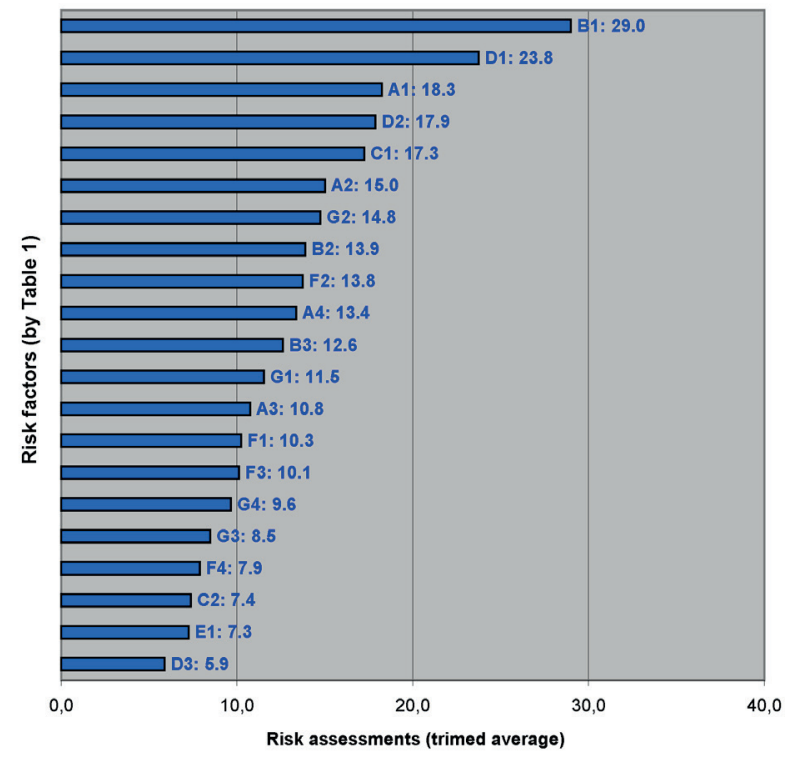

Fig. 3 Ordered risk assessments - option 1 of the station modernisation

${ }^{1}$ Risk assessment is calculated as a product of an RF event severity and its probability, whereas for the event severity a non-linear scale is recommended - an exponential function to base two was chosen for this project.

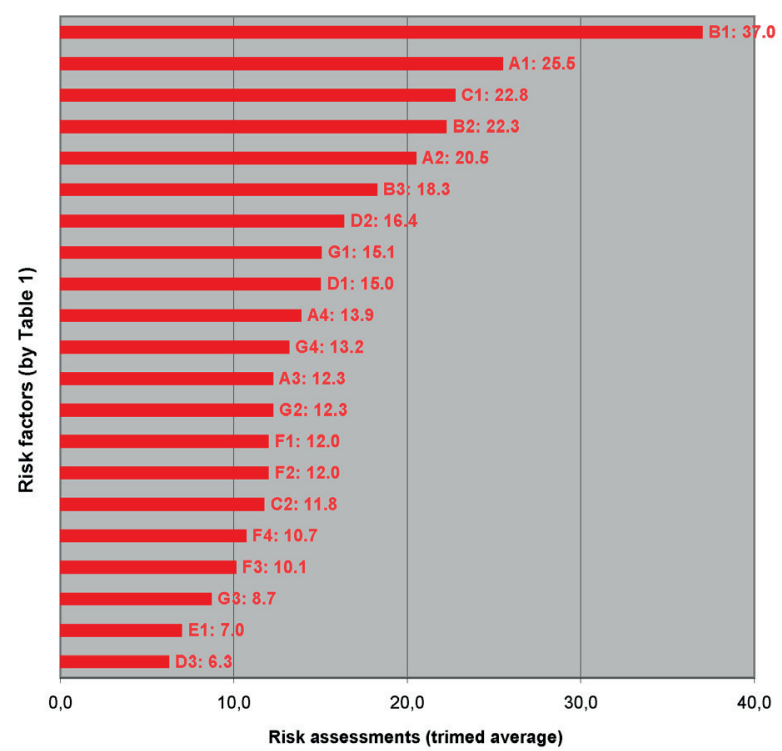

Fig. 4 Ordered risk assessments - option 2 of the station modernisation

Overall, the set of assessments obtained for the Bakov nad Jizerou station layout show a rare occurrence of extreme values. On the contrary, the variability of single answers is quite substantial which points at the diverse emphases of different professions on single segments. The highest (unacceptable) risk for both options is considered by experts to be ensuring finances for the construction; logically, this assessment is more relevant for the more expensive option 2 ("island platform"). There is a higher conditioned risk in this option of not being allocated the finances for the operation and maintenance of the station equipment after its modernisation. Confrontation of risk analysis with the calculated transition times is interesting because the experts assume that option 2 threatens more non-compliance with timetables due to the long transition times which is inconsistent with the calculated times.

In light of all the assessed RFs, the preferable option seems to be the one with semi-island platforms, although the RF of "railway carriage hitting a person on the tracks" significantly exceeded the risk value over the option with grade separation platforms. The 
decision on utility of one of the options over another is, however, not quite unambiguous and unchallengeable, therefore it would be desirable to repeat the whole process of risk analysis with more experts involved or other option/options included.

\subsection{Multi-criteria analysis}

In order to make an assessment of the station modernisation, the project team established seven minimisation criteria out of which for five of them the value of the already completed risk analysis was adopted - see Table 3. Hence, an interconnection of both decision support methods is introduced.

Multi-criteria analysis criteria

Table 3

\begin{tabular}{|c|l|c|l|}
\hline $\begin{array}{c}\text { Ref. } \\
\text { no. }\end{array}$ & Criterion name & Type & Unit of measure \\
\hline 1 & $\begin{array}{l}\text { investment costs (i.e. annual } \\
\text { depreciation) }\end{array}$ & MIN & CZK million \\
\hline 2 & transition time & MIN & minutes \\
\hline 3 & $\begin{array}{l}\text { rail traffic flow disturbance } \\
\text { during the station modernisation } \\
\text { construction works }\end{array}$ & MIN & A1 risk assessment \\
\hline 4 & $\begin{array}{l}\text { damaging the passenger transport } \\
\text { equipment after the station } \\
\text { modernisation due to vandalism }\end{array}$ & MIN & C1 risk assessment \\
\hline 5 & $\begin{array}{l}\text { criminal activity committed at } \\
\text { the station (platforms, underpass, } \\
\text { central crossing) after its } \\
\text { modernisation }\end{array}$ & MIN & C2 risk assessment \\
\hline 6 & $\begin{array}{l}\text { railway carriage hitting a person } \\
\text { on the tracks }\end{array}$ & MIN & $\begin{array}{l}\text { D1 risk } \\
\text { assessment }\end{array}$ \\
\hline 7 & comfort of passengers & MIN & E1 risk assessment \\
\hline
\end{tabular}

For acquiring the numerical values of weights of single criteria, a so-called scoring method (with 1-10 scale) and a so-called Fuller triangle were used. In the analysed set of answers by experts, there are no extreme values nor is the dispersion too large.
Investment costs, railway carriage hitting a person on the tracks and passenger comfort were determined as the most important criteria with $18-20 \%$ weight. For the multi-criteria assessment of the options themselves, the WSA (Weighted Sum Approach) and TOPSIS (Technique for Order Preference by Similarity to Ideal Solution) methods were used. The outcome of both methods concluded that option 2 "island platform" is better - with the WSA method the so-called total utility obtained the value of 0.53 in option 2 against 0.47 in option 1, whereas with the TOPSIS method the utility indicator of option 2 was calculated to be 0.56 against 0.44 in option 1 . It is apparent from the values of the objective function of both methods that the variation between both options is not significant and hence the conclusion on the utility of option 2 is quite ambiguous.

\section{Conclusion}

The overall assessment of both of the proposed options for the Bakov nad Jizerou station modernisation is ambiguous for both of them. This is particularly because of the long transition times in option 1 while investments costs are higher in option 2. A compromise is suggested - the platform configuration of option 2 showing overall higher utility (especially operational), but with a change of the platform type to a semi-island with access via a central foot level crossing which presumes a lower risk exposure, particularly given the modernisation's ability to acquire finances.

Linking the methods of risk and multi-criteria analysis can provide a good tool for choosing the optimal proposal and a valuable clue to search for other preferable alternatives to train station modernisation.

\section{Acknowledgements}

This article was written with support from the Research Project MSM 6840770043.

\section{References}

[1] JACURA, M. et al.: Optimal Layout of Public Mass Transport Transfer Nodes (in Czech). Prague: CTU in Prague (compiled by Faculty of Transportation Sciences, Department of Transporting Systems), 2012. ISBN 978-80-01-05053-8.

[2] TYFA, L. et al.: Modern Trends in Operational and Layout Modifications of Regional Traffic Nodes (in Czech). Prague: CTU in Prague (compiled by Faculty of Transportation Sciences, Department of Transporting Systems), 2010. ISBN 978-80-01-04520-6.

[3] JACURA, M.: Traffic Service in Region (in Czech). Prague, 2010. Doctoral thesis. CTU in Prague, Faculty of Transportation Sciences, Department of Transportation Systems.

[4] PRIBYL, P., A. JANOTA, J. SPALEK: Analysis and Control of Risks in Transport: Tunnels on Roads and Railways (in Czech)]. Praha: BEN - technicka literatura, 2008. ISBN 978-80-7300-214-5. 